\title{
Separation/Analysis of Chrysophanol by Ionic Liquid Loaded $\beta$-Cyclodextrin Polymer Coupled with Ultraviolet Spectrophotometry
}

\author{
Wenhui Ping, Hongyan Xu and Xiashi Zhu* \\ College of Chemistry and Chemical Engineering, Yangzhou University, China
}

\begin{abstract}
A novel method for separation/analysis of chrysophanol (Chry) in drugs is described. The work is based on the utilization of ionic liquid ([C4min] PF6) (IL) loaded $\beta$-cyclodextrin cross-linked polymer (IL- $\beta$-CDCP) for effective adsorption of Chry coupled with ultraviolet spectrophotometry for the analysis of Chry. The inclusion interaction of IL- $\beta-C D C P$ with Chry is studied by FTIR and ${ }^{13} \mathrm{C}-\mathrm{NMR}$. Under the optimum conditions, linear range, Detection Limit (DL) and the relative standard deviation are $0.10-20.0 \mu \mathrm{g} \mathrm{mL}^{-1}, 0.02 \mu \mathrm{g} \mathrm{mL}-1,0.45 \%\left(\mathrm{n}=3, \mathrm{c}=4.0 \mu \mathrm{g} \mathrm{mL}^{-1}\right)$, respectively. This technique is successfully applied for determination of Chry in drug samples.
\end{abstract}

Keywords: Chrysophanol; Ionic Liquid Loaded $\beta$-Cyclodextrin Polymer; Solid-Phase Extraction; Inclusion Interactions; Ultraviolet Spectrophotometry

\section{Introduction}

Chrysophanol (Chry, Figure 1), 1,8-dihydroxy-3methylanthraquinone, is a free anthraquinone compound and a secondary metabolite of medicinal plant rhubarb. Chry has been reported to have many pharmacological effects such as anti-inflammatory activity [1], anti-microbial activity [2] and anti-cancer action [3]. Therefore, the detection of Chry is quite important and interesting. Until now, various techniques have been developed for the determination of Chry to date, including high-performance liquid chromatography [4] and fluorescence spectrophotometry [5]. However, the direct determination with spectrophotometry is difficult owing to matrix effects and low concentration of Chry in samples. Therefore, the necessity of separation/preconcentration procedure of Chry is significant (Figure 1).

Solid-phase extraction (SPE) is of interest because of its simplicity, higher preconcentration factor, and rapid phase separation. Some novel functional materials such as activated carbon [6], zeolite [7], clay [8], different polymeric adsorbents $[9,10]$ and cyclodextrin polymers (CDs) [11] have been used for SPE. CDs have attracted particular attention, due to their unique physico-chemical characteristics, low cost, availability, and presence of various reactive groups on its backbone chain [12]. The functionalization of CDs can, in particular, alter their physical properties to make them suitable for a wide range of applications [13]. Common methods for the functionalization of resin include load technology, bonding technology and sol-gel technology. The load technology is proposed as an alternative green and economic process [14]. Recent

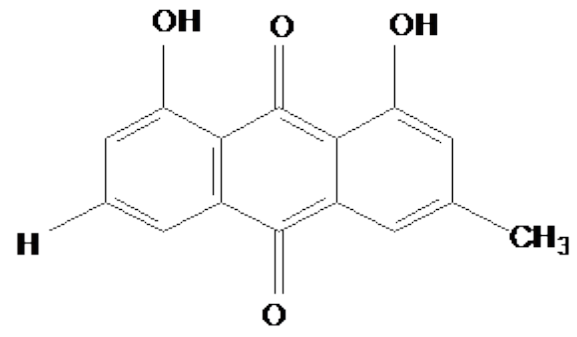

Figure 1: Chemical structure of Chry. research on application of functionalized cyclodextrin for separation/ analysis includes: biological-based chitosan grafted $\beta$-cyclodextrinbenzoic acid [15]; $\mathrm{Fe}_{3} \mathrm{O}_{4} /$ cyclodextrin polymer nanocompositesheavy metals [16]; $\beta$-cyclodextrin-ionic liquid polyurethanes-organic pollutants/ heavy metals [17]. Ionic liquid (IL) load $\beta$-cyclodextrin cross-linked polymer as SPE material seems to be lacking.

In this work, IL was synthesized and loaded onto the $\beta$-cyclodextrin cross-linked polymer (IL- $\beta$-CDCP). FTIR and ${ }^{13} \mathrm{C}$-NMR were used to study the inclusion interactions of IL- $\beta$-CDCP and Chry. The IL- $\beta$ CDCP-solid phase extraction technique followed by ultraviolet spectrophotometry was applied to separation/analysis Chry in real samples.

\section{Experimental}

\section{Materials and Reagents}

Centrifuge (Anke Scientific Instrument Factory, Shanghai), timing multifunctional oscillator (Guohua Limited Company, China), digital water-bath (Guohua Limited Company, China), and $\mathrm{pH}$ meter (Shanghai Jinjke Limited Company, China) were purchased from their respective companies.

FTIR spectra were measured with a Bruker Tensor 27 spectrometer (Bruker Company, Germany). Samples were pressed in KBr pellets and recorded at frequencies from 4000 to $400 \mathrm{~cm}^{-1}$ with a resolution of $4 \mathrm{~cm}^{-1}$. Solid-State NMR (Bruker Company, Germany) spectrum was operated at $400 \mathrm{MHz}$ at room temperature. A SEM Hitachi S-4800 II instrument was used to obtain micrographs of the polymers. Chromatographic separation of analytes was achieved with a LC-10A HPLC (Shimadzu Corporation, Japan), the mobile phase were methanol:water (80:20).

*Corresponding author: Xiashi Zhu, College of Chemistry and Chemical Engineering, Yangzhou University, China, Tel: +86-514-7975244; E-mail: xszhu@yzu.edu.cn

Received August 21, 2013; Accepted September 16, 2013; Published Septembe 19, 2013

Citation: Ping W, Xu H, Zhu X (2013) Separation/Analysis of Chrysophanol by lonic Liquid Loaded $\beta$-Cyclodextrin Polymer Coupled with Ultraviolet Spectrophotometry. Biochem Anal Biochem 2: 138. doi: 10.4172/2161-1009.1000138

Copyright: (c) 2013 Ping W. This is an open-access article distributed under the terms of the Creative Commons Attribution License, which permits unrestricted use, distribution, and reproduction in any medium, provided the original author and source are credited. 
Citation: Ping W, Xu H, Zhu X (2013) Separation/Analysis of Chrysophanol by lonic Liquid Loaded ß-Cyclodextrin Polymer Coupled with Ultraviolet Spectrophotometry. Biochem Anal Biochem 2: 138. doi: 10.4172/2161-1009.1000138

Page 2 of 5

The flow rate of the mobile phase was maintained at $1 \mathrm{~mL} \mathrm{~min}^{-1}$ and the injection volume of sample solution was $10 \mu \mathrm{L} . \beta-\mathrm{CD}, \mathrm{NaOH}, \mathrm{HCl}$, carbinol, ethanol, epoxy chloropropane, Chry were purchased from Shanghai Chemical Reagent Corporation, (China). Stock solution of $100 \mu \mathrm{g} \mathrm{mL} \mathrm{m}^{-1}$ Chry was prepared by directly dissolving it into ethanol and kept in the dark. Maren pills (Taifu Pharmaceutical Corp. Ltd, China), sanhuang tablets (Jinchen Pharmaceutical Corp. Ltd, China).

\section{Synthesis of the IL-B-CDCP}

Hydrophobic ionic liquids $\left[\mathrm{C}_{4} \mathrm{~min}\right] \mathrm{PF}_{6}$ was synthesised according to the literature [18]. $\beta$-cyclodextrin cross-linked polymer $(\beta$-CDCP) was prepared following a published procedure [19]. 5 grams of $\beta$-CDCP were stirred for 3 days in $20 \mathrm{~mL}$ of $\left[\mathrm{C}_{4} \mathrm{~min}\right]\left[\mathrm{PF}_{6}\right]$ medium (ionic liquid: ethanol=1:3) for effective impregnation. The adsorbent was dried at $90^{\circ} \mathrm{C}$ for $24 \mathrm{~h}$. Then the product was sonicated for 1 day and dried at $90^{\circ} \mathrm{C}$ for $24 \mathrm{~h}$ again, and the resulting polymer was IL- $\beta$-CDCP.

\section{Real Sample Pretreatment}

A certain amount of sanhuang tablets/maren pills were grinded into powder. Then $3.0 \mathrm{~g}$ of sanhuang powders $/ 4.5 \mathrm{~g}$ of maren powders were accurately weighed into the beaker, dissolved in $15.0 \mathrm{~mL}$ of ethanol. The above clear liquid was fixed with ethanol into a $25 \mathrm{~mL}$ of flask and stored for determination. The solution was diluted with water before determination. $\mathrm{pH}$ of the solution was always kept the same $(\mathrm{pH}=7.0)$.

\section{Static Adsorption of Chry}

At $15^{\circ} \mathrm{C}$, the amount of Chry $(10 \mathrm{~mL}, 4.0 \mu \mathrm{g} \mathrm{mL}-1)$ and $0.1 \mathrm{~g} \mathrm{IL}-$ $\beta$-CDCP was mixed, controlling the appropriate acidity. The mixture $(10 \mathrm{~mL})$ was shaken on the multifunctional oscillator for $30.0 \mathrm{~min}$ and then centrifugal. Supernatant was determined with ultraviolet spectrophotometry at $317 \mathrm{~nm}$ (the reference solution was distilled water). And retention efficiency of Chry on IL- $\beta$-CDCP was defined as: Adsorption $(\%)=\left[\left(\mathrm{C}_{0}-\mathrm{C}_{\mathrm{e}}\right) / \mathrm{C}_{0}\right] \times 100 \%\left(\mathrm{C}_{0}\right.$ is the initial solution concentration, $\mathrm{C}_{e}$ is the supernatant solution concentration) [15].

\section{Results and Discussion}

\section{Characteristics of the Synthesized Polymer (IL-B-CDCP)}

FTIR analysis: Figure 2 shows the FTIR spectra of IL, $\beta$-CDCP and IL- $\beta$-CDCP, it could be seen that [1] the peaks at $3170 \mathrm{~cm}^{-1}$ and 3125 $\mathrm{cm}^{-1}$ in IL- $\beta$-CDCP are the aromatic part of the $\sigma_{\mathrm{C}-\mathrm{H}}$ vibrations of IL and the characteristic absorption band of imidazole ring in IL from 1404 to

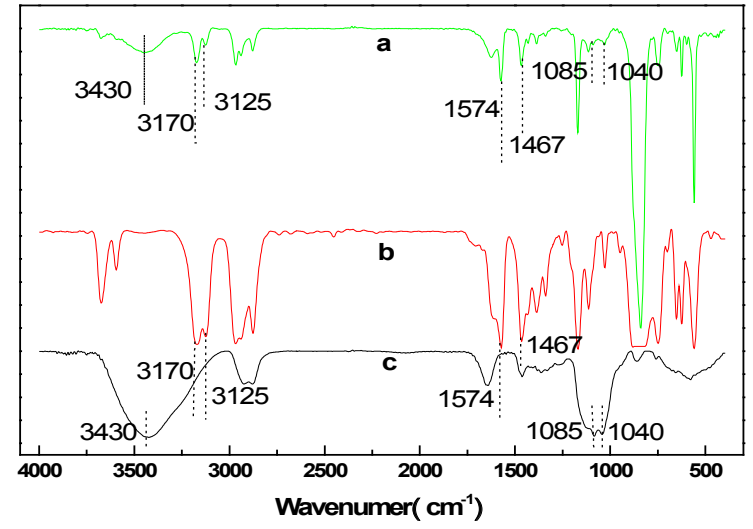

Figure 2: FTIR spectra of (a) IL- $\beta-C D C P$, (b) IL, (c) $\beta-C D C P$.
$1620 \mathrm{~cm}^{-1}$ present in IL- $\beta$-CDCP (curve a, b); [2] the characteristic peak at $3430 \mathrm{~cm}^{-1}$ in IL- $\beta$-CDCP is the spectrum of $\sigma_{\mathrm{C}-\mathrm{O}-\mathrm{H}}$ in $\beta$-CDCP and the peaks from 1000 to $1110 \mathrm{~cm}^{-1}$ in IL- $\beta$-CDCP corresponds to $\sigma_{\mathrm{C}-\mathrm{O}-\mathrm{H}}$ and $\sigma_{\mathrm{C}-\mathrm{O}-\mathrm{C}}$ vibrations in $\beta$-CDCP (curve a c). Therefore, all necessary peaks of $\beta$-CDCP and IL are present in the spectrum of IL- $\beta$-CDCP, which indicates that IL have impregnated onto $\beta$-CDCP successfully (Figure 2).

\section{Analytical Application}

\section{Optimization of Adsorption Step}

Effect of pH: Chry and emodin are all anthraquinone compounds, and always coexist in drugs. In this work, the adsorption behavior of Chry and emodin on IL- $\beta$-CDCP and Chry on $\beta$-CDCP are studied, respectively (Figure 3a). As shown in Figure $3 \mathrm{~b}$ that [1] emodin cannot be adsorpted quantitatively on IL- $\beta$-CDCP (curve b); [2] the retention efficiency of Chry on IL- $\beta$-CDCP (curve a) is always higher than $\beta$-CDCP (curve. c) (Figure $3 \mathrm{c}$ ), this results indicated that the adsoption ability of $\beta$-CDCP for this analyte is greatly improved due to the existence of IL improving the hydrophobicity of polymer; [3] the retention efficiency of Chry on IL- $\beta$-CDCP is above $90.0 \%$ in the range of $\mathrm{pH} 6.0 \sim 10.0$ and lower at $\mathrm{pH}$ (6.0 or) 10.0, it reaches the highest value $97.8 \%$ when $\mathrm{pH}=7.0$. As the dissociation constant $\left(\mathrm{pK}_{\mathrm{a}}\right)$ of Chry is 9.64 [20], the major existence form of Chry was molecule form in neutral solution, the hydrophobicity of molecule form was stronger than its ionic form, so, it was favorable for the Chry enter into IL- $\beta$ CDCP. Thereafter, all experiments were conducted at $\mathrm{pH} 7.0$ (Figure 3).

Effect of the Sample Volume: The amount of Chry was fixed at $4.0 \mu \mathrm{g} \mathrm{mL}{ }^{-1}$, and the volume of the sample solution increased from $5.0 \mathrm{~mL}$ to $50.0 \mathrm{~mL}$. It could be seen from Figure 4 that the retention efficiency was greater than $85 \%$ in the volume of sample $5.0-10.0 \mathrm{~mL}$. In this work, the sample volume of $10.0 \mathrm{~mL}$ was adopted. The adsorption temperature and time of Chry on IL- $\beta$-CDCP were also studied; the experiment was carried out at $15.0^{\circ} \mathrm{C}, 30.0 \mathrm{~min}$.

\section{Optimization of Desorption}

Selection of Eluants: The IL- $\beta$-CDCP could be reproduced by eluants. Chry could be adopted on IL- $\beta$-CDCP due to the hydrophobic grouping of Chry enter into IL- $\beta$-CDCP in neutral solution, so some hydrophobic organic solvent and $\mathrm{NaOH}$ was selected as eluants. Different eluants as ethanol, SDS, $\mathrm{CTAB}, \mathrm{NaOH}$ were investigated

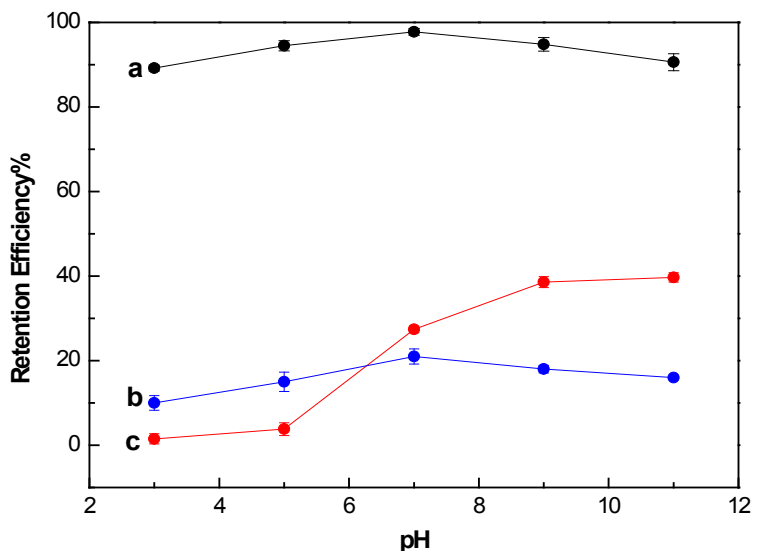

Figure 3: Effect of $\mathrm{pH}$ on retention efficiency of (a) Chry on IL- $\beta$-CDCP (b) emodin on IL- $\beta$-CDCP and (c) Chry on $\beta-C D C P\left(c_{c 0}=4.0 \mu \mathrm{g} \mathrm{mL}^{-1}\right)$. 


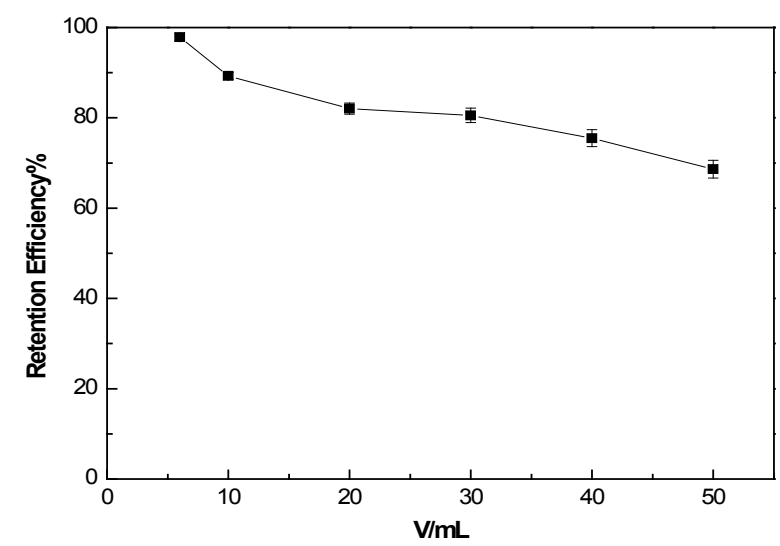

Figure 4: Effect of sample volume on retention efficiency $\left(\mathrm{c}_{\mathrm{co}}=4.0 \mu \mathrm{g} \mathrm{mL} \mathrm{L}^{-1}\right)$

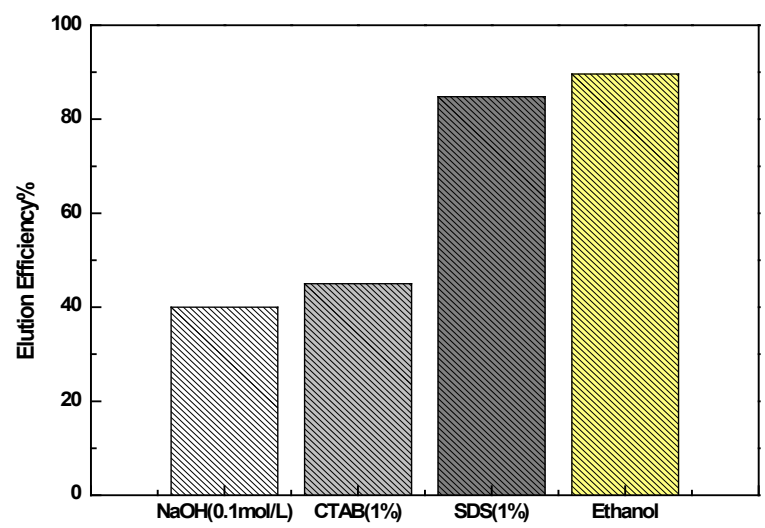

Figure 5: Effect of different dissolvent on elution efficiency.

(Figure 5). The order of elution efficiency was ethanol (89.6\%) SDS (84.8\%) CTAB (45.0\%) NaOH (40.0\%). It indicates that Chry cannot be quantitatively eluted by $\mathrm{NaOH}$ and $\mathrm{CTAB}$, but can be completely eluted by ethanol and SDS, since lots of air bubble was formed in the process of elution in SDS solution and the hydrophobicity of ethanol was stronger than other eluants. So, ethanol was chosen as eluent.

Elution efficiency of Chry with 3.0-8.0 mL of ethanol was studied. The elution efficiency of Chry is above $85 \%$ from $4.0 \mathrm{~mL}$ to $8.0 \mathrm{~mL}$. The preconcentration factor is 2.5 (the quotient of volume before absorption and after elution). Therefore, the optimum volume of ethanol solution chosen for this work is $4.0 \mathrm{~mL}$. In this experiment, the elution temperature and time of Chry on IL- $\beta$-CDCP were studied; the experiment was conducted at $50.0^{\circ} \mathrm{C}, 30.0 \mathrm{~min}$.

Sorption Capacity: The sorption capacity, defined as the maximum amount of Chry sorbed per gram of the polymer IL- $\beta$-CDCP, is an important factor for evaluation of the synthesized IL- $\beta$-CDCP. As shown in Figure 6, when the concentration of Chry is $50 \mu \mathrm{g} \mathrm{mL}^{-1}$, the retention reaches a maximum value. The retention capacity of the polymer is therefore calculated as $3.94 \mathrm{mg} \mathrm{g}^{-1}$.

Effect of Foreign Ions: Determination of Chry $\left(4.0 \mu \mathrm{g} \mathrm{mL}^{-1}\right)$ in the presence of foreign substances was investigated. With a relative error of less than $\pm 5 \%$, the tolerance limit for various foreign substances is in Table 1.

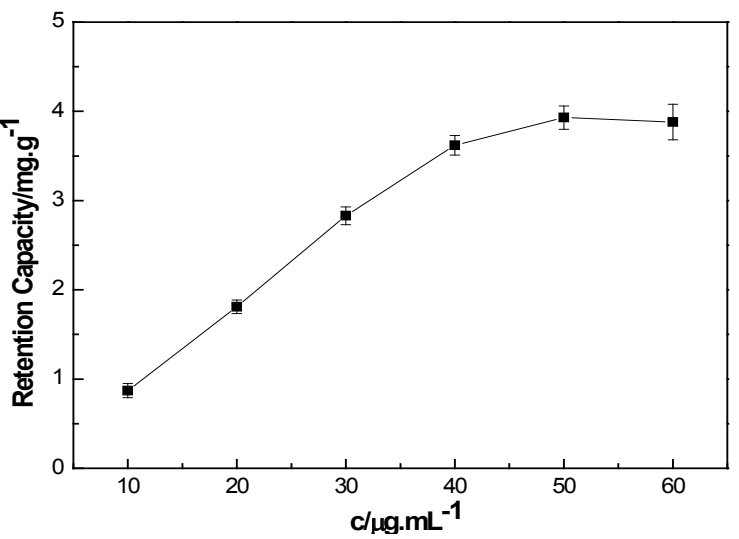

Figure 6: Retention capacity.

\begin{tabular}{|c|c|}
\hline Interferent & Tolerance ratio \\
\hline phenol & 500 \\
\hline $\mathrm{H}_{2} \mathrm{PO}_{4}{ }^{-}$ & 400 \\
\hline tartaric acid, glucose, $\mathrm{Vc}$ & 250 \\
\hline citric acid & 125 \\
\hline $\mathrm{SO}_{4}^{2-}$ & 80 \\
\hline $\mathrm{Mg}^{2+}$ & 30 \\
\hline geniposide, ursolic acid & 5 \\
\hline emodin & 1.2 \\
\hline
\end{tabular}

Table 1: Tolerance of interference ions.

Analytical Parameters: Under optimum conditions described above, IL- $\beta$-CDCP shows a linear calibration curve within the concentration ranging of 0.10 to $20.0 \mu \mathrm{g} \mathrm{mL}^{-1}$. The least square equation is: $\mathrm{A}=0.051 \mathrm{C}\left(\mu \mathrm{g} \mathrm{mL}^{-1}\right)+0.047\left(\mathrm{R}^{2}=0.9930\right)$. The limits of detection (DL), which is defined as $\mathrm{C}_{\mathrm{DL}}=3 \mathrm{~S}_{\mathrm{b}} / \mathrm{m}$, where $\mathrm{S}_{\mathrm{b}}$ is the standard deviation of eleven replicate blank signals and $\mathrm{m}$ is the slope of the linear section of the calibration curve after preconcentration, is found to be $0.02 \mu \mathrm{g}$ $\mathrm{mL}^{-1}$ for a sample volume of $10 \mathrm{~mL}$. The relative standard deviation for three separate batch experiments with $0.1 \mathrm{~g}$ of sorbent for determination of $4.0 \mu \mathrm{g} \mathrm{mL}{ }^{-1}$ Chry in $10 \mathrm{~mL}$ of water is $0.45 \%$. The preconcentration factor was calculated to be 2.5 .

The result of the present method for extraction and determination of Chry are compared with other reported methods [21-24]. Table 2 lists the linear range for the analysis of Chry in real samples with those reported in literatures. It is obvious that the present work has wide linear range, and easy operation (Table 2).

Sample Analysis: As shown in Table 1, emodin was the main interference substance in determination of Chry. The proportion of emodin and Chry was lower than 1.2 in sanhuang tablets/maren pills $[22,25]$, which illustrate the existence of emodin would not influence the determination. The sanhuang tablets/maren pills were analyzed with standard curve method (listed in Table 3). The results of this method and HPLC method were checked by $t$ test method $(\mathrm{P}=0.95$, $\mathrm{f}=3$ ) and had no significant difference (Table 3).

\section{The Adsorption Mechanism of IL- $\beta-C D C P$ and Chry}

The inclusion interactions of IL- $\beta$-CDCP and Chry are the primary mechanism for the adsorption of Chry on IL- $\beta$-CDCP [26]. In this paper, it is evidenced by FTIR and ${ }^{13} \mathrm{C}-\mathrm{NMR}$.

FTIR Analysis: Figure 7 shows the FTIR spectra of the inclusion complex of Chry, IL- $\beta$-CDCP and IL- $\beta$-CDCP-Chry. The intensity of 
Citation: Ping W, Xu H, Zhu X (2013) Separation/Analysis of Chrysophanol by lonic Liquid Loaded ß-Cyclodextrin Polymer Coupled with Ultraviolet Spectrophotometry. Biochem Anal Biochem 2: 138. doi: 10.4172/2161-1009.1000138

\begin{tabular}{|c|c|c|c|}
\hline Method & $\begin{array}{l}\text { Linear range } \\
\left(\mu \mathrm{g} \cdot \mathrm{mL}^{1}\right)\end{array}$ & $\begin{array}{l}\text { Limit of detection } \\
\left(\mu \mathrm{g} \cdot \mathrm{mL}^{-1}\right)\end{array}$ & Reference \\
\hline HPLC & $6.41-102.60$ & - & 21 \\
\hline RP - HPLC & $3.181-101.8$ & - & 22 \\
\hline HPLC - FLD & $0.2560 \sim 25.60$ & - & 23 \\
\hline CPE - HPLC & $0.126-16.2$ & - & 24 \\
\hline $\begin{array}{l}\text { ILS- } \beta-C D C P \text { SPE/ } \\
\text { UV }\end{array}$ & $0.1-20.00$ & 0.02 & $\begin{array}{l}\text { The proposed } \\
\text { method }\end{array}$ \\
\hline
\end{tabular}

Table 2: Comparison with previously reported methods.

\begin{tabular}{|c|c|c|c|}
\hline Sample & Found & HPLC value & Recovery (\%) \\
\hline sanhuang tablets & $3.14 \mathrm{mg} / \mathrm{g}$ & $3.20 \mathrm{mg} / \mathrm{g}$ & 98.13 \\
\hline maren pills & $35.61 \mu \mathrm{g} / \mathrm{g}$ & $36.22 \mu \mathrm{g} / \mathrm{g}$ & 98.32 \\
\hline
\end{tabular}

The sanhuang and maren solution was diluted 100 and 10 times before detection, respectively.

Table 3: The results for the determination of Chry in drug samples.

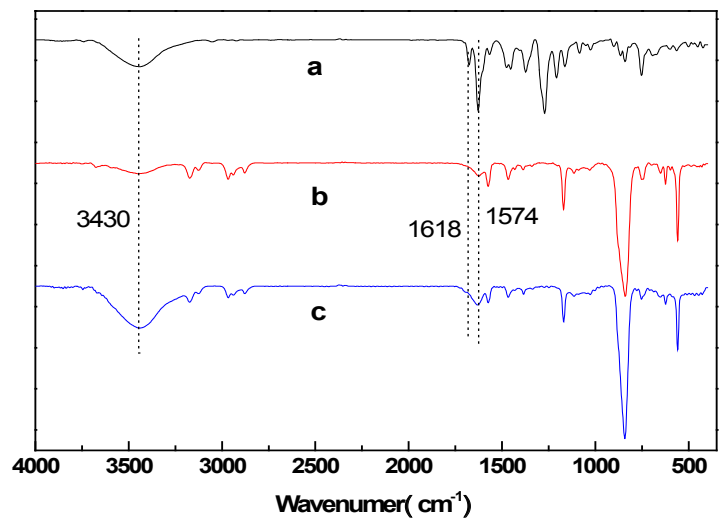

Figure 7: R FTIR spectra (a) Chry, (b)IL- $\beta-C D C P,(c) I L-\beta-C D C P-R h B$.

$\sigma_{\mathrm{C}=\mathrm{C}}$ peaks from 1404 to $1620 \mathrm{~cm}-1$ in imidazole ring of IL- $\beta$-CDCPChry (curve. c) are much higher than that of IL- $\beta$-CDCP (curve. b). It is probably that the IL bond interactions play a crucial role in the inclusion of IL- $\beta$-CDCP-Chry. $\sigma_{\mathrm{O}-\mathrm{H}}$ Peak $\left(3430 \mathrm{~cm}^{-1}\right)$ in IL- $\beta$-CDCPChry (curve. c) increases, which demonstrated that the hydroxy part in Chry (curve. a) is enclosed in the hydrophobic cavity of IL- $\beta$-CDCPChry.

Solid-State NMR Analysis: ${ }^{13} \mathrm{C}-\mathrm{NMR}$ spectra of the IL- $\beta$-CDCP and IL- $\beta$-CDCP-Chry are presented in Figure 8 . The splitting of $\mathrm{C}_{1}$ peak in IL- $\beta$-CDCP (curve a) disappear completely after adsorbing Chry, which illustrates the formation of the inclusion IL- $\beta$-CDCP-Chry (curve b). This result indicated that the existence of Chry makes the conformation of CD ring in IL- $\beta$-CDCP more symmetrical and $\mathrm{C}_{1}$ is almost in the same chemical environment [27] (Figure 8).

Inclusion constants: The inclusion constant $\mathrm{K}$ is a significant parameter which illustrates inclusion properties of host-guest molecules. The incolusion complex can be easily formed at a higher $\mathrm{K}$. The inclusion constants of the monomers of two kind of polymers ( $\beta$ $\mathrm{CD}$ and IL $+\beta-\mathrm{CD})$ and Chry were measured. The form of inclusion and the inclusion constant can be caculated by UV-visible abs

orption spectroscopy and Hildebrrand-Benesi equation [28,29].

The double reciprocal plots of the $\beta$-CD-Chry inclusion complex (curve. a) and (IL+ $\beta$-CD)-Chry inclusion complex (curve. b) are shown in Figure 9. It can be concluded that $\beta-\mathrm{CD}$ and $\mathrm{IL}+\beta-\mathrm{CD}$ form the

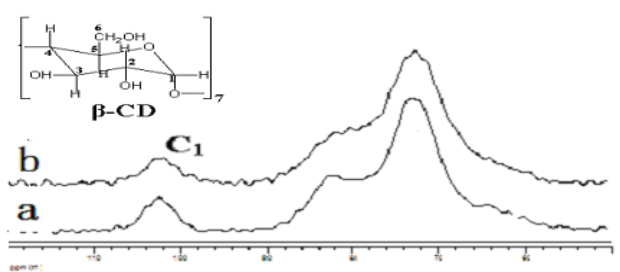

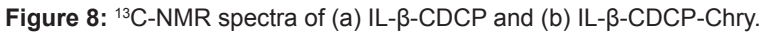
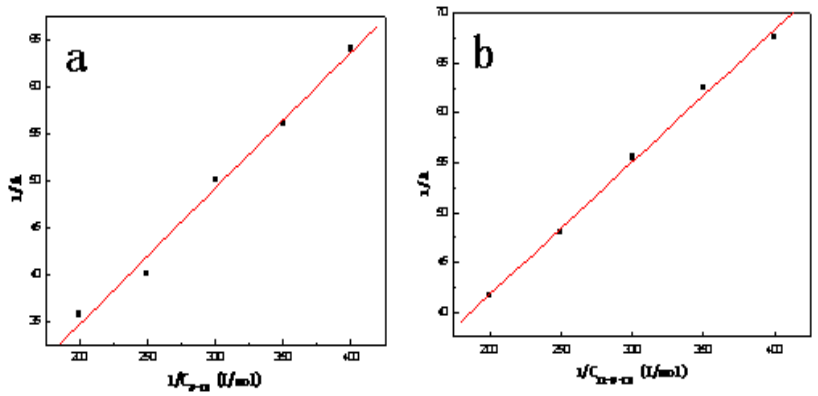

Figure 9: Double reciprocal plot of the (a) $\beta-C D$-Chry inclusion complex and (b) $(\mathrm{IL}+\beta-\mathrm{CD})$-Chry inclusion complex.

inclusion complexes with Chry at ratio of 1:1. The two double reciprocal plots show good linearity with correlation coefficients of 0.9946 for $\beta$-CD and 0.9983 for IL $+\beta-C D$. The inclusion constant of $\beta$-CD-Chry inclusion complex K is $38.54 \mathrm{~L} \mathrm{~mol}^{-1}$ and $113.64 \mathrm{~L} \mathrm{~mol}^{-1}$ for (IL+ $\beta-\mathrm{CD}$ )Chry inclusion complex, which are acquired by the slope and intercept of the double reciprocal plots. Inclusion constant reflects inclusion ability of host molecule to guest molecule. All above illustrates that the inclusion ability of IL $+\beta-C D$ towards Chry is stronger than of $\beta-C D$. That is one reason why IL- $\beta$-CDCP has higher adsorption efficiency than $\beta$-CDCP (Figure 9).

\section{Conclusion}

IL- $\beta$-CDCP used as solid phase extraction material (SPE) to preconcentrate/separate Chry coupled with ultraviolet spectrophotometry for the analysis of Chry was established. The proposed method has some advantages, such as increase of contact area between IL and water, reduction of amount of IL, little loss of IL and was an easy, safe and inexpensive methodology for the separation and determination of Chry in drugs.

\section{Acknowledgements}

The authors acknowledge the financial support from the National Natural Science Foundation of China $(20875082,21155001)$ and Jiangsu Key Laboratory of Environmental Material and Environmental Engineering and the Foundation of Excellence Science and Technology Invention Team in Yangzhou University

\section{References}

1. Kim SJ, Kim MC, Lee BJ, Park DH, Hong SH, et al. (2010) Anti-Inflammatory activity of chrysophanol through the suppression of NF-kappaB/caspase-1 activation in vitro and in vivo. Molecules 15: 6436-6451.

2. Sosa KG, Alvarez NV, Lübben P, Pena-Rodriguez LM (2006) Chrysophanol, an antimicrobial anthraquinone from the root extract of colubrina greggii, $\mathrm{J}$. Mex. Chem. Soc 50: 76-78.

3. Lee MS, Cha EY, Sul JY, Song IS, Kim JY (2011) Chrysophanic acid blocks proliferation of colon cancer cells by inhibiting EGFR/mTOR pathway. Phytother Res 25: 833-837. 
Citation: Ping W, Xu H, Zhu X (2013) Separation/Analysis of Chrysophanol by lonic Liquid Loaded ß-Cyclodextrin Polymer Coupled with Ultraviolet Spectrophotometry. Biochem Anal Biochem 2: 138. doi: 10.4172/2161-1009.1000138

Page 5 of 5

4. Wu DL, Chen SY, Jin CS (2012) HPLC simultaneous determination of pinostrobin and chrysophanol in hull of carya cathayensis sarg, Chin. J. Pharm. Anal 32: 249-251.

5. Wang BQ, Pang ZG, Li SY (1991) Determination of content of emodin chrysophanol, chrysophanic acid and rhein by ß-cyclodextrin single molecular micelle fluorometry, J. Chin. Pharm. Univ 22: 375-378.

6. Hennion MC (1999) Solid-phase extraction: method development, sorbents and coupling with liquid chromatography. J Chromatogr A 856: 3-54.

7. LiuY, Guo YP, Gao W, Wang Z, Ma Y, et al. (2012) Simultaneous preparation of silica and activated carbon from rice husk ash, J. Clean. Prod 32: 204-209.

8. Mafra L, Blasco T (2012) Chapter four - structural characterization of zeolites by advanced solid state NMR spectroscopic methods, Annu. Rep. NMR Spectro 77: 259-351.

9. Carriazo JG (2012) Influence of iron removal on the synthesis of pillared clays: A surface study by nitrogen adsorption, XRD and EPR, Appl. Clay Sci 67-68: 99-105

10. Pan BC, Xiong Y, Li AM, Chen JL, Zhang QX, et al. (2002) Adsorption of aromatic acids on an aminated hypercrosslinked macroporous polymer, React. Funct. Polym. 53: 63-72.

11. Yamasaki H, Makihata $Y$, Fukunaga $K$ (2006) Efficient phenol removal of wastewater from phenolic resin plants using crosslinked cyclodextrin particles, J. Chem. Technol. Biotechnol 81: 1271-1276.

12. Crini G (2005) Recent developments in polysaccharide-based materials used as adsorbents in wastewater treatment, Prog. Polym. Sci 30: 38-70.

13. Szejtli J (1998) Introduction and General Overview of Cyclodextrin Chemistry. Chem Rev 98: 1743-1754.

14. Ren $R$, Wang $Y$, Zhang $R$, Gao S, Zhang $H$, et al. (2011) Solvent (ionic liquid) impregnated resin-based extraction coupled with dynamic ultrasonic desorption for separation and concentration of four herbicides in environmental water. Talanta 83: 1392-1400.

15. Chai KG, Ji HB (2012) Dual functional adsorption of benzoic acid from wastewater by biological-based chitosan grafted $\beta$-cyclodextrin. Chem. Eng J 203: 309-318.

16. Badruddoza AZ, Tay AS, Tan PY, Hidajat K, Uddin MS (2011) Carboxymethyl$\hat{l}^{2}$-cyclodextrin conjugated magnetic nanoparticles as nano-adsorbents for removal of copper ions: synthesis and adsorption studies. J Hazard Mater 185: $1177-1186$.
17. Mahlambi MM, Malefetse TJ, Mamba BB, Krause RW (2010) $\beta$-Cyclodextrinionic liquid polyurethanes for the removal of organic pollutants and heavy metals from water: synthesis and characterization. J. Polym. Res 17: 589-600.

18. Wang Y, You J, Ren R, Xiao Y, Gao S, et al. (2010) Determination of triazines in honey by dispersive liquid-liquid microextraction high-performance liquid chromatography. J Chromatogr A 1217: 4241-4246.

19. Zhu X, Wu M, Gu Y (2009) Beta-cyclodextrin-cross-linked polymer as solid phase extraction material coupled with inductively coupled plasma mass spectrometry for the analysis of trace Co(II). Talanta 78: 565-569.

20. Li F, Ding ZT, Cao QE (2007) Determination of dissociation constant of 5 kinds of rhubarb anthraquinones derivatives, Chin. J. Chin. Mater. Med 32 166-168.

21. Chen JR, Xie F, Yin XF (2011) Content determination of emodin and chrysophanol in Niuhuang Jiedu dropping pill by HPLC, Chin. J. Her. Med. 30: 500-502.

22. Wang J, Zhang YM, Li JR (2009) Determination and relative analysis of emodin and chrysophanol in Sanhuang tablets, J. Hebei Polytech. Univ 31: 93-99.

23. Han YY, Wang LY, Du GL (2010) HPLC- fluorescence determination of rhein emodin, chrysophanol in Dongle plaster, Chin. J. Pharm. Anal 30: 1016-1018.

24. Zhang JW, Wei YH, Wu QY, Li BX, Duan HG, et al. (2010) Simultaneous determination of aloe-emodin, emodin and chrysophanol in rat plasma by HPLC-CPE, Chin. J. Chin. Hosp. Pharm. J 30: 911-915.

25. Wang QY (2006) Determination the content of emodin and chrysophanol in Maren pills by HPLC, Chin. J. Chin. Pharm 9: 622-623.

26. Yang ZJ, Chai KG, Ji HB (2011) Selective inclusion and separation of cinnamaldehyde and benzaldehyde by insoluble $\beta$-cyclodextrin polymer. Sep. Purif. Technol 80: 209-216.

27. Ye LJ, Yue YD, Qun C (2002) Preparation and characterization of the crystalline inclusion complexes between cyelodextrins and poly $(1,3-$ dioxolane), Sci. China, Ser. B 32: 51-59.

28. Bao ZJ, Dai L, Miao ZT (2004) Determinat ion of the dissociat ion constants of magnolol and honokiol by UV spectrophotometry, J. Yunnan Univ. (Nat Sci. Ed.) 26: 66-69.

29. Zarzycki PK, Lamparczyk H (1998) The equilibrium constant of betacyclodextrin-phenolphtalein complex; influence of temperature and tetrahydrofuran addition. J Pharm Biomed Anal 18: 165-170.t 